\title{
PENGARUH LOCUS OF CONTROL DAN EFIKASI DIRI TERHADAP KINERJA KARYAWAN DENGAN KETERIKATAN KARYAWAN SEBAGAI VARIABELINTERVENING PADA PT SEMENPADANG
}

\author{
Putri Intan Suci Pulungan ${ }^{1)}$, Harif Amali Rivai ${ }^{2)}$ \\ ${ }^{1)}$ Program Studi Magister Manajemen, Fakultas Ekonomi, \\ Universitas Andalas Putriintansucipulungan@gmail.com \\ ${ }^{2)}$ Program Studi Magister Manajemen, Fakultas Ekonomi, \\ Universitas Andalas Harifamali@gmail.com
}

\begin{abstract}
This study aims to determine the effect of variable of locus of control and self efficacy on job performance and employee engagement.The Sampling techniques Jacob Chen, the respondents in this research totalled 204 respondents. This study uses data analysis techniques using SPSS version 15.0 software, which previously used validity, reliability, inner model, hypothesis testing, and mediation effect tests. The results of the analysis show that all independent variables in this study have aninfluence on the dependent variable, either partially or simultaneously, while the locus of control variable on performance through employee engagement has no mediating effect, and self-efficacy on employee performance through employee engagement has a partial mediationrelationship.
\end{abstract}

Keywords : Locus of Control,Self Efficacy, Job Performance, Employee Engagement

\begin{abstract}
Abstrak Penelitian ini dilakukan bertujuan untuk mengetahui pengaruh Locus of Control dan efikasi diri terhadap kinerja karyawan dan keterikatan karyawan. Teknik pengambilan sampel menggunakan Jacob Chen, responden dalam penelitian ini berjumlah 204 responden. Penelitian ini mengggunakan teknik Analisis Data menggunakan software SPSS versi15.0, dimana sebelumnya digunakan uji validitas, reliabilitas, inner model, uji hipotesis, dan uji efek mediasi. Hasil analisis menunjukkan bahwa seluruh variabel independen dalam penelitian ini memiliki pengaruh terhadap variabel dependennya, baik secara parsial maupun simultan,sedangkan variabel locus of control terhadap kinerja melalui keterikatan karyawan tidak memiliki efek mediasi, dan efikasi diri terhadap kinerja karyawan melalui keterikatan karyawan memiliki hubungan mediasi parsial.
\end{abstract}

Kata Kunci :Locus of Control, Efikasi Diri, Kinerja Karyawan, Keterikatan Karyawan

\section{A. PENDAHULUAN}

Kesuksesan pencapaian tujuan organisasi tergantung kepada sumber daya yang dimiliki, tidak terkecuali sumber daya manusia. Tanpa adanya sumber daya manusia, maka sumber daya lainya tidak akan berguna dan kurang bermanfaat untuk mencatat tujuan organisasi. Suatu organisasi bisa dikatakan berhasil dalam membangun sumber daya manusia apabila karyawan-karyawannya bekerja dengan baik sesuai kebutuhan organisasi. Keberhasilan organisasi dapat dilihat dari kinerja karyawan-karyawannya, jika kinerja karyawan baik, maka organisasi bisa mencapai tujuannya dan begitu juga sebaliknya, jika kinerja karyawan buruk, maka organisasi sulit untuk mencapai tujuannya, untuk itu organisasi harus mampu membangun sumber daya manusianya yang dapat dilihat dari kinerja karyawannya.

Kinerja karyawan merupakan hasil kerja yang dihasilkan oleh suatu pegawai berdasarkan tugas dan tanggung jawab yang diberikan oleh organisasi. Pencapaian kinerja karyawan ini berdampak terhadap pencapaian tujuan organisasi. Seorang karyawan di tuntut untuk menghasilkan kinerja yang baik, agar perusahaan mampu mencapai tujuannya. Jika 
perusahaan mampu menjaga kinerja karyawannya, maka perusahaan tersebut bisa dikatakan berhasil dalam mengelola sumber daya manusianya (Hasibuan, 2016)

Kinerja pegawai dipengaruhi beberapa faktor-faktor yaitu, faktor internal karyawan dan faktor eksternal karyawan, dari faktor-faktor tersebutlah kinerja karyawan dapat dinilai, jika faktor tersebut dapat dijaga dengan baik, akan dapat meningkatkan kualitas hasil kerja karyawan, begitu juga sebaliknya, jika faktor tersebut tidak dapat dijaga dengan baik, maka kinerja karyawan juga tidak akan baik, baik buruknya kinerja karyawan sangat tergantung pada kemampuan organisasi untuk menjaga faktor-fakot utama tersebut, tugas utama organsasi yang harus menjaga faktor-faktor tersebut, karena dengan faktor-faktor tersebut suatu organisasi akan mampu mencapai tujuannya (Hasibuan, 2016).

Penelitian ini dilakukan di PT. Semen Padang, merupakan perusahaan yang bergerak dalam bidang pengelolaan bahan baku dan produk semen. PT. Semen Padang merupakan organisasi yang cukup besar dalam memiliki banyak kayawan serta sektor pekerjaan yang cukup beragam, sehingga cukup sulit untuk melakukan kontrol terhadap kinerja karyawannya. Selain itu banyaknya sektor pekerjaan yang ada di PT. Semen Padang membuat karyawan memiliki rasa keterikan dengan perusahaan berbeda dengan sektor lainya.

Berdasarkan hasil pra survei pada karyawan departemen produksi di PT. Semen Padang, terdapat beberapa fakta yang menunjukkan rendahnya kinerja karyawan yang berasal dari factor intern yaitu kurangnya efikasi diri dan kurangnya keterikatan karyawan dengan perusahaan yang menyebabkan si karyawan mengalami penurunan terhadap kinerja mereka.

Pencapaian kinerja karyawan dapat dipengaruhi oleh faktor yang berasal dari dalam diri individu yaitu keterikatan karyawan (Sulistyo, 2017). Keterikatan karyawan adalah rasa keterikan karyawan terhadap organisasi atau perusahaan yang menauinginya, karyawan yang memiliki rasa keterikatan yang tinggi terhadap organisasi atau perusahaan, akan memikirkan kemajuan atau perkembangan organisasi tersebut dan sebaliknya jika karyawan tidak memiliki keterikatan yang lebih di suatu organisasi atau perusahaan, maka perusahaan tersebut hanya memikirkan kepentingan pribadinya tanpa memikirkan kepentingan atau perkembangan organisasi atau perusahaan tersebut. Ikatan yang terjadi antara karyawan dengan organisasi atau perusahaan lebih bersifat kognitif atau memiliki rasa emosional yang tinggi akan keterhubungan dengan organisasi atau perusahaan(Gallup, 2013).

Karyawan yang memiliki rasa emosional yang tinggi terhadap keterhubungan dengan organisasi atau perusahaan memiliki semangat kerja yang lebih tinggi, bekerja tidak hanya sebatas bekerja, tetapi bekerja dengan baik dan sungguh-sungguh, menyelesaikan pekerjaan tepat waktu tanpa menunda-nunda pekerjaan yang telah dibebankan dan menggunakan jam kerja untuk menyelesaikan pekerjaan tepat waktu. Setiap perusahaan atau organisasi memliki program khusus untuk meningkatkan rasa keterikan karyawan dengan organisasi atau perusahaan, baik yang dilakukan dengan memberikan pelatihan kepada karyawan atau dengan memberikan fasilitas atau layanan yang memadai bagi karyawan sehingga menciptakan kepuasan kerja karyawan, komitmen karyawan serta perilaku organisasi karyawan. Karyawan dilibatkan secara aktif dalam menentukan arah dan tujuan organisasi atau perusahaan guna memberikan kebebasan bagi karyawan untuk ikut dalam menentukan tujuan dan pencapaian tujuan organisasi atau perusahaan. Dengan adanya keterlibatkan aktif ini karyawan akan merasa memiliki rasa tanggung jawab yang lebih besar terhadap organisasi atau perusahaan.

Pencapaian kinerja karyawan dapat dipengaruhi oleh faktor yang berasal dari dalam diri individu yaitu locus of control. Menurut Widyaningrat (2014) locus of control adalah tindakan dalam diri seseorang dalam mengendalikan diri mereka yang berkaitan dengan kesuksesan maupun kegagalan. Setiap manusia memiliki kemampuan untuk mengontrol diri mereka,baik dalam Menentukan hal-hal yang baik, maupun dalam menjaga diri dari hal yang akan berdampak buruk. Locus of control sangat erat kaitanya dengan cara kerja seseorang dengan image diri mereka, ketika seseorang mampu mengendalikan diri dengan baik, tau kelebihan dan kekurangan diri, maka orang tersebut akan memiliki cara kerja yang lebih baik,terencana dengan baik serta sistematis. Locus of control internal yaitu pengaruh diri terhadap hal-hal yang berkaitan dari dalam diri, seperti motivasi, control diri, keyakinan dan hal yang bersumber 
langsung dari diri sendiri. Sedangkan locus of control eksternal yaitu hal-hal yang berkaitan dengan diri yang bersumber langsung dari lingkungan luar diri seperti suatu kebetulan, keberuntungan atau lucky dan nasib. Dari kedua jenis locus of control ini manusia mampu melakukan control terhadap apa yang mereka inginkan untuk hidup dan diri mereka.

Selain locus of control yang juga mempengaruhi kinerja karyawan yang bersumber dari dalam diri sendiri yaitu efikasi diri. Efikasi diri merupakan kemampuan manusia dalam mengetahui kemampuan dan kekurangan diri sendiri, efikasi diri sangat erat kaitanya dengan kontrol terhadap diri sendiri, setiap manusia dilahirkan memiliki kemampuan untuk mengenali diri sendiri, baik terlahir atau muncul secara alamiah dari pengalaman hidup maupun dari bantuan lingkungan sekitar (Medhayanti,2015). Efikasi diri berpengaruh besar terhadap kemampuan individu dalam mengambil suatu keputusan yang berkaitan dengan diri sendiri dalam mencapai tujuan yang diinginkan, ketika seseorang memiliki efikasi diri yang baik, maka seseorang tersebut mampu mengambil keputusan yang baik bagi dirinya dan sebaliknya jika seseorang belum memiliki efikasi diri yang baik dalam dirinya, maka keputusan yang diambil cenderung bersifat buru-buru hanya untuk menyesaikan permasalahan sesaat (Medhayanti, 2015). Berdasarkan uraikan diatas, maka peneliti tertarik untuk melakukan penelitian tentang "Pengaruh Locus of Control dan Self Efficacy Terhadap Kinerja Karyawan dengan Employee Engagement Sebagai Variabel Mediasi Pada PT. SemenPadang".

Berdasarkan penjelasan diatas, maka kerangka konseptual penelitian ini dapat digambarkan pada Gambar 1 berikut ini.

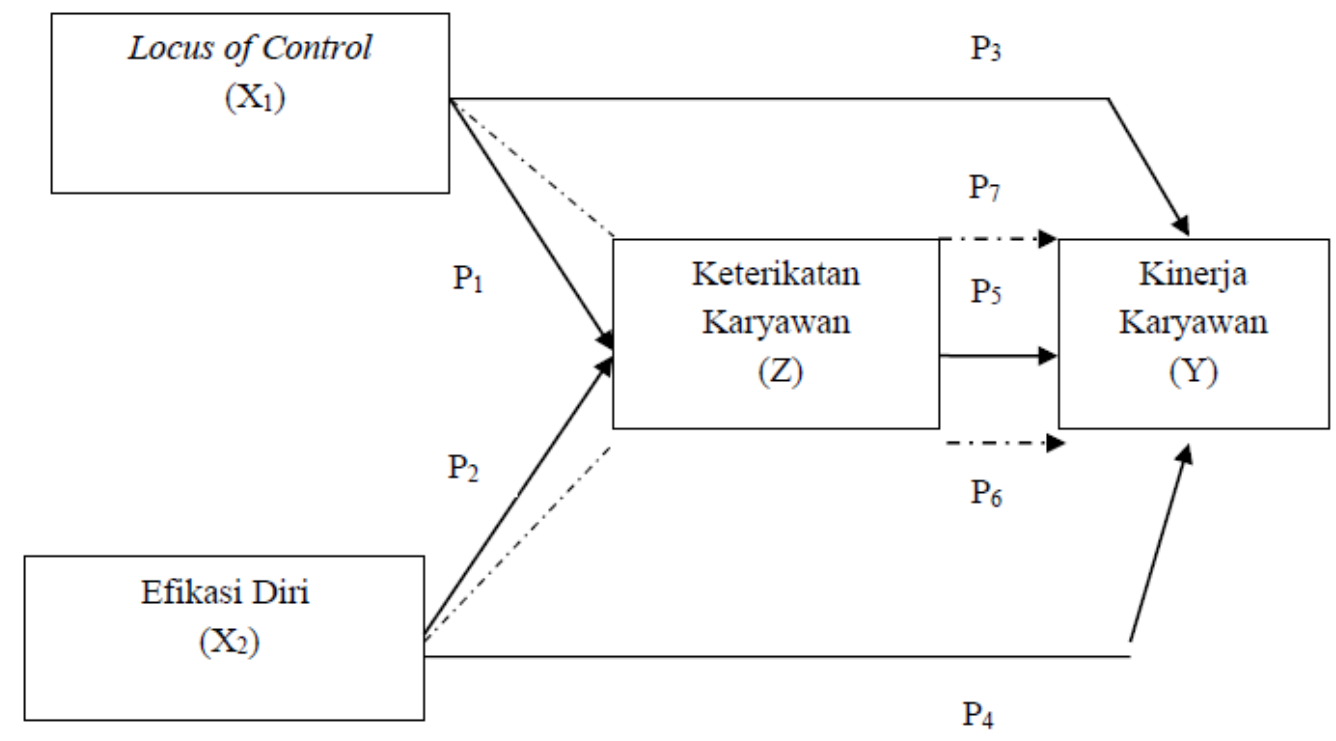

Gambar 1 Kerangka Konseptual

Pada penelitian ini terdapat tujuh hipotesis, diantaranya:

$\mathrm{H} 1$ : Locus of Control berpengaruh positif signifikan terhadap keterikatan karyawan

H2 : Efikasi Diri berpengaruh positif signifikan terhadap keterikatan karyawan

H3 : Locus of Control berpengaruh positif signifikan terhadap keterikatan karyawan

H4 : Efikasi Diri berpengaruh positif signifikan terhadap kinerja karyawan

H5 : Keterikatan karyawan berpengaruh positif signifikan terhadap kinerja karyawan

H6:Locus of Control berpengaruh positif dan signifikan terhadap kinerja karyawan yang dimediasi oleh keterikan karyawan

H7:Efikasi Diri berpengaruh positif dan signifikan terhadap kinerja karyawan yang dimediasi oleh keterikatan karyawan 


\section{B. METODEPENELITIAN}

Penelitian ini merupakan penelitian kuantitatif. Data didapatkan dari PT semen Padang. Teknik pengumpulan sampel dilakukan dengan purposive sampling. Sehingga didapatkan 204 sampel perusahaan dari 2.345 total populasi. Adapun definisi operasional variabel penelitian dan penggunaan rumus dapat terlihat pada tabel berikut ini:

\section{Tabel 1}

\section{Definisi Operasional Variabel}

\begin{tabular}{|c|c|c|c|c|}
\hline No & Variabel & Defenisi Operasional Variabel & Indikator & Sumber \\
\hline 1 & $\begin{array}{c}\text { Kinerja } \\
\text { Karyawan } \\
(\mathrm{Y})\end{array}$ & $\begin{array}{l}\text { Kinerja karyawan merupakanhasil } \\
\text { dari kerja atau usaha seorang } \\
\text { karyawan, baik dari segi kualitas } \\
\text { kerja yang dihasilkan maupun } \\
\text { kuantitas kerja yang dihasilkan } \\
\text { seorang karyawan dalammencapai } \\
\text { tujuan organisasi yang telah } \\
\text { ditetapkan. }\end{array}$ & $\begin{array}{ll}\text { 1. } & \text { Kualitas } \\
\text { 2. } & \text { Kuantitas } \\
\text { 3. } & \text { Ketepatan } \\
& \text { Waktu } \\
\text { 4. } & \text { Efektifitas } \\
\text { 5. } & \text { Kemandirian }\end{array}$ & $\begin{array}{c}\text { Hasibuan } \\
\text { (2016) }\end{array}$ \\
\hline 2 & $\begin{array}{c}\text { Keterikatan } \\
\text { Karyawan } \\
\text { (Z) }\end{array}$ & $\begin{array}{l}\text { Keterikatan karyawan adalah } \\
\text { hubungan yang bersifit terikat, } \\
\text { baik secara fisik, emosional } \\
\text { maupun secara kognitif antara } \\
\text { seseorang dalam suatu organisasi } \\
\text { atau perusahaan dalam sebuah } \\
\text { pekerjaan. }\end{array}$ & $\begin{array}{ll}\text { 1. } & \text { Budaya } \\
\text { 2. Indikator } \\
\text { Sukses } \\
\text { 3. Pengertian } \\
\text { Prioritas } \\
\text { 4. Komunikasi } \\
\text { 5. Inovasi }\end{array}$ & $\begin{array}{c}\text { Federman } \\
(2009)\end{array}$ \\
\hline 3 & $\begin{array}{c}\text { Locus of } \\
\text { Control } \\
\left(\mathrm{X}_{1}\right)\end{array}$ & $\begin{array}{l}\text { Locus of } \text { Control adalah } \\
\text { kemampuan seseorang } \\
\text { individu dalam mengendalikan } \\
\text { dirinya sendiri akan suatu minat } \\
\text { atau kemampuan } \\
\text { dimilikinya. }\end{array}$ & $\begin{array}{l}\text { 1. PotensiPerilaku } \\
\text { 2. Harapan } \\
\text { 3. Nilai Unsur } \\
\text { Penguat } \\
\text { 4. Suasana } \\
\text { Psikologis }\end{array}$ & $\begin{array}{l}\text { Rotter } \\
(2015)\end{array}$ \\
\hline 4 & $\begin{array}{l}\text { Efikasi diri } \\
\left(\mathrm{X}_{2}\right)\end{array}$ & $\begin{array}{l}\text { Efikasi diri merupakan } \\
\text { kepercayaan atau keyakinan yang } \\
\text { bersumber dari dalam diri sendiri } \\
\text { dalam melakukan apapun dan } \\
\text { menyelesaikan pekerjaan apapun } \\
\text { guna mencapai tujuan dan } \\
\text { keinginan yang telah ditetapkan. }\end{array}$ & $\begin{array}{l}\text { 1. Pengalaman } \\
\text { Pertama } \\
\text { 2. Pengalaman } \\
\text { MasaLalu } \\
\text { 3. Kemampuan } \\
\text { Verbal } \\
\text { 4. KeadaanFisik }\end{array}$ & $\begin{array}{l}\text { Ormrod } \\
(2012)\end{array}$ \\
\hline
\end{tabular}

\section{HASIL DAN PEMBAHASAN}

Berdasarkan formulasi yang dijelaskan pada definisi operasional variabel di atas maka akan dilakukan serangkaian pengujian untuk melihat hasil hipotesis. Yang mana tujuan dilakukannya beberapa pengujian ini untuk memastikan bahwa model layak untuk di uji. 


\section{Uji Composite Reliability}

Uji reliabilitas digunakan untuk menguji konsistensi atau kehandalan suatu isntrumen penelitian dalam mengukur konsep yang harus diuji. Uji reliabilitas dapat diukur dengan dua kriteria yaitu compositereliability dan cronbachalpha. Suatu variable dikatakan reliable jika nilai composite reliable dan cronbach alpha $>0,70$.

\section{Tabel 2}

Cronbach's Alpha dan Composite Reliability dan Average Variance Extracted (AVE)

\begin{tabular}{|l|r|r|r|r|}
\hline & \multicolumn{1}{|l|}{$\begin{array}{l}\text { Cronbach's } \\
\text { Alpha }\end{array}$} & rho_A & $\begin{array}{l}\text { Average } \\
\text { Composite } \\
\text { Reliability }\end{array}$ & $\begin{array}{l}\text { Variance } \\
\text { Extracted } \\
\text { (AVE) }\end{array}$ \\
\hline EE & 0,971 & $\mathbf{0 , 9 7 9}$ & $\mathbf{0 , 9 7 4}$ & $\mathbf{0 , 7 0 5}$ \\
\hline KK & $\mathbf{0 , 9 2 2}$ & $\mathbf{0 , 9 3 0}$ & $\mathbf{0 , 9 4 5}$ & $\mathbf{0 , 8 1 1}$ \\
\hline LC & $\mathbf{0 , 9 6 5}$ & $\mathbf{0 , 9 6 8}$ & $\mathbf{0 , 9 6 8}$ & $\mathbf{0 , 6 5 7}$ \\
\hline SE & $\mathbf{0 , 9 1 7}$ & $\mathbf{0 , 9 2 5}$ & $\mathbf{0 , 9 4 2}$ & $\mathbf{0 , 8 0 3}$ \\
\hline
\end{tabular}

\section{Model Struktural (Inner Model)}

Uji ini dilakukan dengan melihat nilai R-square yang merupakan uji goodness of fit. Penilaian dengan PLS dimulai dengan melihat nilai R-square untuk setiap variabel dependen. Perubahan nilai R-square dapat digunakan untuk melihat pengaruh variabel independen terhadap variabel dependen, apakah mempunyai pengaruh yang substansif. Model struktural dalam penelitian ini dapat dilihat dalam table dibawah.

\section{Tabel 3}

Uji Goodness of Fit - Inner Model (Structure Model)

\begin{tabular}{|c|c|c|}
\hline & R Square & R Square Adjusted \\
\hline EE & 0.638 & 0.634 \\
\hline KK & 0.618 & 0.612 \\
\hline
\end{tabular}

\section{Uji Hipotesis}

Untuk melakukan uji hipotesis dapat dilakukan dengan menggunakan fungsi bootstrapping pada SmartPLS 3.0. untuk menerima/menolak hipotesis dapat dilakukan dengan melihat nilai probabilitas dan t-statistik. Hipotesis akan diterima jika t-statistik > t-tabel $(1,96)$, dan p-value $<0,05$. 


\section{Tabel 4}

Path Coefficient

\begin{tabular}{|l|c|c|c|c|c|}
\hline & $\begin{array}{c}\text { Original } \\
\text { Sample (O) }\end{array}$ & $\begin{array}{c}\text { Sample Mean } \\
(\mathbf{M})\end{array}$ & $\begin{array}{c}\text { Standard } \\
\text { Deviation } \\
(\text { STDEV) }\end{array}$ & $\begin{array}{c}\text { T Statistics } \\
(\mid \mathbf{O} \text { (STDEV|) }\end{array}$ & P Values \\
\hline $\begin{array}{l}\text { EE -> } \\
\text { KK }\end{array}$ & 0.260 & 0.262 & 0.083 & 3.154 & 0.002 \\
\hline LC -> EE & 0.139 & 0.138 & 0.053 & 2.606 & 0.009 \\
\hline $\begin{array}{l}\text { LC -> } \\
\text { KK }\end{array}$ & 0.292 & 0.287 & 0.062 & 4.671 & 0.000 \\
\hline SE -> EE & 0.705 & 0.707 & 0.043 & 16.423 & 0.000 \\
\hline SE -> KK & 0.339 & 0.343 & 0.104 & 3.267 & 0.001 \\
\hline
\end{tabular}

Uji Efek Mediasi

\section{Tabel 5}

Specific Indirect Effect

\begin{tabular}{|l|c|c|c|c|r|}
\hline & $\begin{array}{c}\text { Original } \\
\text { Sample } \\
(\mathbf{O})\end{array}$ & $\begin{array}{c}\text { Sample Mean } \\
(\mathbf{M})\end{array}$ & $\begin{array}{c}\text { Standard } \\
\text { Deviation } \\
\text { (STDEV) }\end{array}$ & $\begin{array}{c}\text { T Statistics } \\
(\mid \mathbf{O} / \text { STDEV|) }\end{array}$ & P Values \\
\hline $\begin{array}{c}\text { LC -> EE -> } \\
\text { KK }\end{array}$ & 0.036 & 0.037 & 0.021 & 1.743 & 0.082 \\
\hline $\begin{array}{l}\text { SE -> EE -> } \\
\text { KK }\end{array}$ & 0.184 & 0.185 & 0.059 & 3.113 & 0.002 \\
\hline
\end{tabular}

Sumber: Olah Data Primer, 2020

Tabel di atas menunjukkan uji pengaruh tidak langsung variabel independen terhadap variabel dependen. Berdasarkan tabel di atas dapat disimpulkan bahwa pengaruh tidak langsung variabel locus of control terhadap kinerja karyawan adalah tidak signifikan, karena nilai t-statistik $(1,743)>\mathrm{t}$-tabel $(1,96)$ dan p-value $(0,082)>0,05$. Dan pengaruh tidak langsung variabel keterikatan karyawan terhadap kinerja karyawan adalah tidak signifikan, karena nilai t-statistik $(1,743)>\mathrm{t}$ - tabel $(1,98)$ dan p-value $(0,082)>0,05$.

\section{Pembahasan}

\section{Locus of Control Terhadap Keterikatan Karyawan}

HasilpengujianmenunjukkanbahwavariabelLocusofControlberpengaruhpositifdansign ifikan terhadap keterikatan karyawan. Dari hasil pengujian yaitu semakin besar Locus of Control yang dirasakan karyawan maka akan meningkatkan rasa keterikatan antar karyawan. Hasil penelitian ini sejalan dengan hasil penelitian Jati (2019) bahwa locus of control berpengaruh positif dan signifikan terhadap keterikatan karyawan. Semakin baik seorang karyawan dalam mengontrol dirinya, baik itu dari pengaruh internal maupun eksternal akan dapat meningkatkan rasa keterikatan karyawan denganperusahaan 


\section{Efikasi Diri Terhadap Keterikatan Karyawan}

Hasil pengujian menunjukkan bahwa efikasi diri berpengaruh positif dan signifikan terhadap keterikatan karyawan. Hal tersebut menjelaskan bahwa efikasi diri mampu menciptakan rasa keterikatan pada karyawan PT Semen Padang. Artinya, semakin tinggi efikasi diri yang dimiliki oleh karyawan maka karyawan tersebut tidak akan mengalami disonansi emosi yang mana akan menyebabkan penurunan keterikatan karyawan meskipun nantinya di hadapkan pada emotional job. Hal uji hipotesis ini sesuai dengan hasil penelitian yang dilakukan oleh Jolly (2013) yang menyatakan bahwa efikasi diri secara positif berpengaruh terhadap rasa keterikatan karyawan yang dimiliki oleh karyawan. Karyawan yang merasa dirinya begitu berharga dan berarti cenderung untuk melakukan yang terbaik dalam setiap tugas dan tanggung jawabnya, baik sebagai anggota organisasi maupun sebagai individual.

\section{Locus of Control Terhadap Kinerja Karyawan}

Hasil pengujian menunjukkan bahwa Locus of Control berpengaruh positif dan signifikan terhadap kinerja karyawan. Hal ini menjelaskan bahwa locus of control memegang fungsi kendali dalam peran individu dan juga keterlibatan kinerja karyawan didalam sebuah perusahaan yang mana sangat dipengaruhi oleh locus of control. Hal ini sesuai dengan penelitian yang dilakukan oleh Hemawan dan Kaban (2014) menyebutkan bahwa locus of control berpengaruh positif dan signifikan terhadap kinerja karyawan. Internal locus of control dan eksternal locus of control berpengaruh secara positif terhadap kinerja karyawan sesuai dengan teori yang mengatakan bahwa secara umum, seseorang dengan kecenderungan internal locus of control akan mampu menghasilkan kinerja yangbaik.

\section{Efikasi Diri Terhadap Kinerja Karyawan}

Hasil Pengujian menunjukan bahwa Efikasi Diri berpengaruh positif dan signifikan terhadap kinerja karyawan. Hal ini menjelaskan bahwa jika efikasi diri tercipta dengan baik pada karyawan PT Semen Padang, maka kinerja karyawan akan semakin baik. Meskipun demikian, pimpinan perlu melakukan komunikasi dua arah dengan bawahannya, memberikan kesempatan untuk menjelaskan isu-isu penting bagi pekerjaan dan kehidupannya, serta melibatkan dan menunjukkan rasa hormat kepada karyawan. Hal ini sesuai dengan penelitian Ardi (2013) menyatakan bahwa efikasi diri secara positif berpengaruh terhadap kinerja yang dimiliki oleh karyawan, artinya semakin tinggi efikasi diri yang dimiliki oleh seorang karyawan, maka karyawan tersebut akan mengeluarkan usaha yang cukup besar agar mereka dapat meraih kinerja yangtinggi.

\section{Keterikatan Karyawan Terhadap Kinerja Karyawan}

Hasil Pengujian menunjukan bahwa Keterikatan Karyawan berpengaruh positif dan signifikan terhadap kinerja karyawan Hal ini menjelaskan semakin tinggi keterikatan karyawa di PT.Semen Padang maka akan meningkatkan kinerja karyawan PT. Semen Padang, hal ini sesuai dengan penelitian yang di lakukan oleh Wishada (2016) yang menyatakan bahwa keterikatan karyawan memiliki dampak positif dan signifikan terhadap kinerja karyawan disebabkan karena karyawan memiliki rasa keterikatan yang tinggi dengan perusahaan yang mana mereka bekerja tidak hanya demi mendapatkan upah saja tetapi juga demi kepentingan dan kemajuanperusahaan.

\section{Keterikatan Karyawan Memediasi Locus of Control Terhadap Kinerja Karyawan}

Hasil pengujian menunjukkan bahwa adanya peran mediasi keterikatan karyawan pada hubungan locus of control terhadap kinerja pada PT.Semen Padang. Artinya, ada pengaruh tidak langsung variabel keterikatan karyawan terhadap kinerja karyawan secara signifikan. Dimana, peran locus of control akan lebih signifikan ketika langsung mempengaruhi kinerja karyawan. Hal ini disebabkan oleh rasa puas yang dirasakan oleh karyawan karena adanya kepastian yang diberikan oleh perusahaan yang membuat karyawan lebih terbuka dan terikat pada perusahaan 
sehingga keinginannya untuk bekerja meningkat dan lebih loyal pada perusahaan. Hal ini sesuai dengan penelitian Putra (2015) dan Ardi (2016) menyebutkan bahwa locus of control berpengaruh positif dan signifikan terhadap kinerja karyawan yang dimediasi oleh keterikatan karyawan, artinya karyawan yang memiliki kontrol yang baik terhadap dirinya memiliki rasa keterikatan yang tinggi terhadap perusahaan, sehingga karyawan tidak hanya bekerja demi mendapatkan penghasilan, tetapi bekerja demi memajukan perusahaan, karyawan lebih fokus dalam bekerja sehingga akan dapat meningkatakan kinerjakaryawan.

\section{Keterikatan Karyawan Memediasi Efikasi Diri Terhadap Kinejera Karyawan}

Hasil pengujian menunjukan bahwa adanya peran mediasi keterikatan karyawan pada hubungan locus of control terhadap kinerja kayawan pada PT. Semen Padang. Hal ini disebabkan oleh rasa keyakinan yang dimiliki oleh karyawan karena adanya keyakinan tersebut sehingga membuat karyawan lebih percaya diri dan mampu dalam membuat keputusan serta mengerjakan tugas yang ditanggungjawabkan kepadanya sehingga kinerja karyawan tersebut akan meningkat dan lebih bersemangat menerima tanggung jawab dari perusahaan.

Hal ini sejalan dengan penelitian Cherian dan Jolly (2013) dan Wahyuni (2015) menyatakan bahwa efikasi diri secara positif berpengaruh terhadap kinerja yang dimiliki oleh karyawan yang dimediasi oleh keterikatan karyawan, semakin baik efikasi diri karyawan, maka akan dapat meningkatkan keterikatan karyawan dengan perusahaan, dengan adanya keterikatan yang kuat ini, membuat karyawan bersungguh- sungguh dalam bekerja yang berdampak terhadap peningkatan kinerja karyawan, serta penelitian.

\section{PENUTUP}

Berdasarkan hasil analisis dan pembahasan pada bab sebelumnya maka dapat diambil kesimpulan sebagai berikut: Locus of Control berpengaruh positif dan signifikan terhadap keterikatan karyawah pada kantor PT Semen Padang. Efikasi Diri berpengaruh positif dan signifikan terhadap keterikatan karyawan pada kantor PT Semen Padang. Locus of Control berpengaruh positif dan signifikan terhadap kinerja karyawan pada kantor PT Semen Padang. Efikasi Diri berpengaruh positif dan signifikan terhadap kinerja karyawan pada kantor PT Semen Padang. Keterikatan karyawan berpengaruh positif dan signifikan terhadap kinerja karyawan pada kantor PT Semen Padang. Locus of Control berpengaruh positif dan signifikan terhadap kinerja karyawan yang dimediasi oleh keterikatan karyawan pada kantor PT Semen Padang. Efikasi diri berpengaruh positif dan signifikan terhadap kinerja karyawan yang dimediasi oleh keterikatan karyawan pada kantor PT SemenPadang.

Secara umum terdapat beberapa implikasi yang dapat diajukan berhubungan dengan masing- masing variabel penelitian. PT Semen Padang dapat lebih memperhatikan masalah yang dimiliki pegawainya dan juga memotivsi pegawainya untuk dapat membantu rekan kerja yang menemui kesulitan dan menyarankan kepada pegawai agar mengikuti kegiatan yang di adakan. PT Semen Padang dapat memperhatikan hal-hal yang membuat karyawan menjadi nyaman dalam bekerja agar karyawan tidak ingin untuk melepaskan diri dari pekerjaannya misalnya dengan lebih memperhatikan fasilitas yang dibutuhkan oleh karyawan. PT Semen Padang dapat memperhatikan keadaan yang di alami oleh karyawannya, apa pencapaian yang akan di tuju oleh karyawan sehingga ia memiliki tanggung jawab atas pekerjaannya dengan bantuan baik itu dari keluarga ataupun dari teman sehingga karyawan akan semangat bekerja dan meningkatkan kualitas kinerjanya. PT Semen Padang hendaknya memberikan kendali yang besar kepada pegawainya atas persoalan yang terjadi di departemennya masing-masing berupa locus of control dan memberikan peluang besar untuk kemerdekaan dan kebebasan dalam cara melakukan atau menyelesaikan pekerjaannya agar pegawai PT Semen Padang dapat lebih meningkatkan rasa keterikatan secara maksimal. PT Semen Padang memberikan kepercayaan dan tanggung jawab penuh terhadap karyawannya dalam menyelasaikan pekerjaan yang 
dipegangnya.

Peneliti menyadari bahwa hasil yang ditemukan memiliki sejumlah kekurangan dan kelemahan yang disebabkan adanya keterbatasan yang dimiliki, diantaranya tesis ini masih jauh dari kesempurnaan, penelitian ini hanya menganalisis aspek locus of control dan efikasi diri terhadap kinerja karyawan dengan keterikatan karyawan sebagai variable intervening. Sampel dalam penelitian ini hanya terfokus pada pegawai PT Semen Padang. Jumlah sampel dalam penelitian ini hanya berjumlah 204 pegawai di PT Semen Padang.

\section{E. DAFTAR PUSTAKA}

Abdallah, A. B. (2016). An Integrated Model of Job Involvement, Job Satisfaction and Organizational Commitment: A Structural Analysis in Jordan's. Scientific Research Publishing Inc. 9, 28-53.

Aftab,H.I.(2012).AStudyofJobSatisfactionandIT'sImpactonthePerformanceintheBanking Industry of Pakistan. International Journal of Business and Social Science, 3 ,174180.

Agus Apriansyah, H. A. (2018). HUBUNGAN ANTARA EFIKASI DIRI DENGAN KEMAMPUAN PENGAMBILAN KEPUTUSAN KARIR SISWA MAN 2 KOTA BENGKULU.JurnalIlmiahBimbingandanKonselingFKIPUniversitasBengkulu,1-10.

Agyeman, C. M. (2014). Employee Demographic Characteristics and Their Effects on Turnover and Retention in MSMEs. International Journal of Recent Advances in Organizational Behaviour and Decision Sciences (IJRAOB), 1-18.

Akbar, S. (2018). Analisa Faktor-Faktor yang Mempengaruhi Kinerja Karyawan. JIAGANIS, $1-17$.

Albdour, A. A. (2014). Employee Engagement and Organizational Commitment: Evidence from Jordan. International Journal Of Business, 19, 193-212.

Albrecht, S. L. (2010). Handbook of Employee. Cheltenham, UK • Northampton, MA, USA: Edward Elgar Publishing Limited.

Ali Abbaas Albdour, I. I. (2014). Employee Engagement and Organizational Commitment: Evidence from Jordan. INTERNATIONAL JOURNAL OF BUSINESS, 1-21.

ArnoldBBakker,M.T.(2012).Proactivepersonalityandjobperformance:Theroleofjobcrafting and work engagement. Human Relations,1359-1378.

Arnold B. Bakker, P. M. (2010). Weekly work engagement and performance: A study among starting teachers. Journal of Occupational and Organizational Psychology, 189-206.

Ary Sinar Deany, I. M. (2016). PENGARUH SELF ESTEEM, SELF EFFICACY, LOCUS OF CONTROL, DAN EMOTIONAL STABILITY PADA KINERJA PENGELOLA ANGGARAN BELANJA UNIVERSITAS UDAYANA. E-Jurnal Ekonomi dan Bisnis Universitas Udayana, 3713-3740.

Astrid Yuniar Nurbaity, H. S. (2013). PENDEKATAN ENGAGEMENT DALAM MEMBANGUN KINERJA PEGAWAI. EKOBIS Vol.14, No.2,44-58.

Bakker, M. (2010). Weekly work engagement and performance: A study among starting teachers. 
Journal of Occupational and Organizational Psychology. 83, 189-206.

Dematria Pringgabayu, E. F. (2018). MENINGKATKAN KINERJA KARYAWAN MELALUI PERAN MEDIASI KEPUASAN DAN KETERIKATAN KARYAWAN ATAS MOTIVASI DAN LINGKUNGAN KERJA PERUSAHAAN ASURANSI DI INDONESIA. EKOBIS - Ekonomi Bisnis Vol. 23 No. 1, 12-20.

Desak Made Putri Sanjiwani, I. G. (2016). PENGARUH LOCUS OF CONTROL, GAYA KEPEMIMPINAN DAN KOMITMEN ORGANISASI PADA KINERJA AUDITOR KANTOR AKUNTAN PUBLIK. E-Jurnal Akuntansi Universitas Udayana, 920-947.

Dewi, R. P. (2017). HUBUNGAN EFIKASI DIRI DENGAN PENGAMBILAN KEPUTUSAN KARIR PADA MAHASISWA TINGKAT AKHIR FAKULTAS PSIKOLOGI UNIVERSITAS MERCU BUANA YOGYAKARTA. InSight, Vol. 19 No. 2, 1-13.

Fadila. (2016). Mengembangkan Motivasi Belajar Melalui Locus Of Control dan Self Esteem. Jurnal Pendidikan Islam vol. 1, no 01, 2016, 1-18.

Henis Fiqih Amalini, M. A. (2016). PENGARUH LOCUS OF CONTROL TERHADAP KEPUASAN KERJA DAN KINERJA (Studi pada Karyawan Perusahaan Daerah Air Minum (PDAM) Kota Malang). Jurnal Administrasi Bisnis (JAB)|Vol. 35 No. 1, 1-10.

Hilda C.F. Nahusona, M. R. (2004). ANALISIS FAKTOR-FAKTOR YANG BERPENGARUH TERHADAP KEINGINAN KARYAWAN UNTUK PINDAH. JURNAL STUDI MANAJEMEN \& ORGANISASIVolume 1, Nomor 2, 1-16.

Iwan Restu Ary, A. A. (2019). PENGARUH SELF EFFICACY DAN LOCUS OF CONTROL TERHADAP KINERJA KARYAWAN . E-Jurnal Manajemen, Vol. 8, No. $1,1-24$.

J,A.(2014).DeterminantsofEmployeeEngagementandTheirImpactonEmployeePerformance. International Journal of Productivityand Performance Management. Vol. 63 No. 3, 308- 323.

Jack Henry Syauta, E. A. (2012). The Influence of Organizational Culture, Organizational Commitment to Job Satisfaction and Employee Performance (Study at Municipal Waterworks of Jayapura, Papua Indonesia). International Journal of Business and Management Invention, 69-76.

James L. Gibson, J. M. (2012). ORGANIZATIONS BEHAVIOUR, STRUCTURE,

PROCESSES.

New York: McGraw-Hill.

javed, M. (2014). Determinants of Job Satisfaction and its Impact on Employee Performance and Turnover Intentions. International Journal of Learning \& Development, 1-22.

Khan M R, Z. J. (2010). The Impacts of Organizational Commitment on Employee Job Performance. European Journal of Social Sciences. 15 (3), 292-298.

Lewiuci P G, M. R. (2016). Pengaruh Employee Engagement terhadap Kinerja Karyawan pada Perusahaan Keluarga Produsen Senapan Angin. AGORA. 4 (2), 101-107.

Mary Lynn Berry, M. L. (2019). CAREER DECISION MAKING SELF EFFICACY IN COLLEGE STUDENTS. InSight, Vol. 21 No. 1, 1693-2552. 
Muhammad Shollih Abdurrahman, R. P. (2019). Pengaruh Motivasi Kerja Otonom dan Internal Locus of Control Terhadap Kinerja Karyawan dengan Employee Engagement Sebagai Variabel Mediasi. Performance. Volume 26 Nomor 2, 66-76.

Mujiasih, E. (2015). HUBUNGAN ANTARA PERSEPSI DUKUNGAN ORGANISASI (PERCEIVED ORGANIZATIONAL SUPPORT) DENGAN KETERIKATAN

(EMPLOYEE ENGAGEMENT). Jurnal Psikologi Undip Vol.14 No.1, 40-51.

\section{Mulyana, S. (2019). INTERVENSI KEADILAN DAN ENGAGEMENT TERHADAP KEPEMIMPINAN DALAM MENINGKATKAN KOMITMEN ORGANISASIONAL KARYAWAN PERUSAHAAN DI JABODETABEK. JURNAL MANAJEMEN VOL. 16 NO. 1,, 78-108.}

Mustamu, P. G. (2016). PENGARUH EMPLOYEE ENGAGEMENT TERHADAP KINERJA KARYAWAN PADA PERUSAHAAN KELUARGA PRODUSEN SENAPAN ANGIN. AGORA, 1-7.

Mustika, A. (2013). PENGARUH BUDAYA ORGANISASI, TERHADAP KINERJA KARYAWAN DENGAN VARIABEL KEPUASAN KERJA SEBAGAI VARIABEL

INTERVENING. Among Makarti Vol.6 No.12, Desember 2013, 1-25.

Negin Memari, O. M. (2013). The Impact of Organizational Commitment on Employees Job Performance. "A study of Meli bank". INTERDISCIPLINARY JOURNAL OF CONTEMPORARY RESEARCH IN BUSINESS, 1-18.

NiMadeNurcahyani,I.D.(2016).PENGARUHKOMPENSASIDANMOTIVASITERHADAP KINERJA KARYAWAN DENGAN KEPUASAN KERJASEBAGAI VARIABEL INTERVENING. E-Jurnal Manajemen Unud, Vol. 5, No.1, 500-532.

Ologbo C. Andrew, S. S. (2012). Individual Factors and Work Outcomes of Employee Engagement. Procedia - Social and Behavioral Sciences 40, 298-508.

Purnomo, R. (2010). PENGARUH KEPRIBADIAN, SELF-EFFICACY, DAN LOCUS OF CONTROL TERHADAP PERSEPSI KINERJA USAHA SKALA KECIL DAN MENENGAH. Jurnal Bisnis dan Ekonomi (JBE), 144-160.

Sandeep Kular, M. G. (2008). Employee Engagement: A Literature Review. Kingston University: Kingston Business School.

Siswanto,B.(2019).PENGARUHMOTIVASIKERJADANDISIPLINKERJATERHADAP KINERJAKARYAWAN.JIMS-JurnalIlmiahManajemenSumberDayaManusia,1-11.

Suharto, S. N. (2019). The Impact of Organizational Commitment on Job Performance. International Journal of Economics and Business Administration, 189-206.

Suprayogi, T. T. (2017). LOCUS OF CONTROL DAN KINERJA KARYAWAN: UJI KOMPARASI. Jurnal Riset Manajemen dan Bisnis (JRMB) Fakultas Ekonomi UNIAT, 131-138.

Tiffani Chandrilika Kusuma, A.P.(2017). PENERAPAN STRATEGI EMPLOYER BRANDING DAN EMPLOYEE VALUE PROPOSITION UNTUK MENCIPTAKAN EMPLOYEE ENGAGEMENT (Studi Pada PT Bank Central Asia Tbk). Jurnal Administrasi Bisnis (JAB) Vol. 50 No. 5, 1-9.

Venna Trilolita Putri Ardi, E. S. (2017). PENGARUH SELF EFFICACY TERHADAP EMPLOYEE ENGAGEMENT DAN KINERJA KARYAWAN (Studi pada 
Karyawan PT Telekomunikasi Indonesia Regional V Surabaya). Jurnal Administrasi Bisnis (JAB) Vol. 52 No. 1, 1-10.

Weihui Fu, S. P. (2014). The Impact of Caring Climate, Job Satisfaction, and Organizational Commitmenton Job Performan ceof Employee sina China'sInsurance Company.Journal of Business Ethics,339-349.

Wilmar Schaufeli,M.S.(2007). Work Engagement" An Emerging Psychological Conceptan dIts Implications for Organizations". Managing Social and Ethical Issues in Organizations, 135-177. 